\title{
La colección de arte español de William Stirling Maxwell en Pollok House, Glasgow
}

\author{
GLORIA ALBERCA RODRÍGUEZ
}

Recibido: 15-04-2019

Aprobado: 24-06-2019

\section{RESUMEN}

El siglo XIX supondrá un punto de inflexión en el mercado artístico europeo. La introducción de España en dicho mercado dará lugar a una nueva tendencia en el coleccionismo que se interesará especialmente por el arte del Siglo de Oro español. La finalidad de esta investigación será llevar a cabo el análisis de una de las colecciones más relevantes en todo Reino Unido por convertirse en paradigma del nuevo contexto que acontecía en dicho siglo. Por ello, se analizará la colección del escocés Stirling Maxwell, y en particular la llamada colección Pollok que ha llegado a nuestros días, ubicada en Glasgow, así como los motivos que le llevaron a interesarse por el coleccionismo de arte español y las consecuencias que tuvo para la nueva perspectiva hacia la cultura y el arte españoles en la sociedad anglosajona.
PALABRAS
CLAVE:
Pollok/Stirling
Maxwell/Siglo
XIX/Glasgow/

Coleccionismo/Siglo de Oro/arte español.

\section{ABSTRACT}

The nineteenth century was a decising point in the european artistic market. The introduction of Spain into that market would build a new collectionism interested by Spanish Golden Age art. The finality of this research will be the analysis of one of the most important collections throughout the United Kingdom because it became the paradigm of new century context. For that, the collection of the Scottish Stirling Maxwell will be analysed and in particular, the Pollok collection that has survived, placed in Glasgow, and the reasons of the interest of the Scottish collector about Spanish Art and the consequences that it had for the new perspective of the anglosaxon society about the Spanish culture and art.

KEY WORDS: Pollok/Stirling Maxwell/19th Century/Glasgow/ Collectionism/Golden Age/Spanish Art. 
Sir William Stirling Maxwell fue un historiógrafo escocés del siglo XIX, quien se interesó por los artistas españoles, especialmente del Siglo de Oro, lo que le llevó a crear una importante colección de arte que hoy se expone en el palacio familiar. Centrándose en la parte de la colección hoy denominada Pollok Collection, ubicada en Pollok House, en Glasgow, Escocia, compuesta por más de cincuenta obras de las que adquirió a lo largo de sus viajes, gracias a amigos marchantes, como Valentín Carderera o Martínez de Gradilla, así como el gran número de obras adquiridas en las subastas de Christie's, procedentes de la Galería Española del Rey Luis Felipe en 1853 .

El interés suscitado por el arte español en Gran Bretaña durante el siglo XIX vendrá impulsado por la visión romántica que se tendrá de este país, como destino exótico para aquellos eruditos anglosajones con ansias de nuevos conocimientos y nuevo contenido para ampliar sus colecciones particulares. Esto dará lugar a que, a lo largo del siglo, lleguen a España - como anteriormente habían hecho en Italia con motivo del Grand Tour - numerosos marchantes de arte, que pondrán de moda el Barroco español y las representaciones contemporáneas en el mundo anglosajón.

Uno de los grandes exponentes de este fenómeno será el escocés Sir William Stirling Maxwell, con la amplia colección de arte y literatura que formó. Tanto fue el amor e interés que profesó por las tierras ibéricas y sus artistas que recopiló una importante cantidad de información sobre éstos en su obra Annals of Artists of Spain, publicada en 1848 , compuesta por cuatro volúmenes ${ }^{1}$, y que se erigió como una notable fuente historiográfica en el mundo británico.

A pesar de la importancia que supuso el papel del escocés en la difusión del arte español, la historiografía no ha otorgado suficiente atención ni al personaje en sí ni a su excelsa colección; y especialmente, la historiografía española. Tanto es así, que su obra no ha sido traducida en su totalidad, aún hoy, a nuestro idioma a pesar de la importancia que tiene para el conocimiento del arte y los artistas españoles, por la perspectiva diferente que otorga sobre dicho tema.

\footnotetext{
1 En un principio, estaba compuesta por tres volúmenes, a los que más tarde se le sumó un cuarto ilustrado con numerosos talbotipos.
} 
Si bien las primeras colecciones artísticas tal y como entendemos el término hoy día surgieron en el Renacimiento, el coleccionismo sufrirá una evolución a lo largo del tiempo. En el siglo XIX nos encontramos con una reivindicación del coleccionismo y la promoción artística como forma de prestigio en las esferas aristocráticas, aunque con la entrada en este siglo encontraremos un nuevo tipo de coleccionismo de carácter meramente burgués, donde se dará preminencia a los gustos más variados y personales, dejando, en parte, a un lado las modas artísticas que marca el mercado. Esto implica que con el paso del tiempo, el interés personal por el arte haya desembocado en una preservación cultural, por lo que muchas de las colecciones que se formaron entonces están hoy a la vista del público, conservadas en los edificios que los propios coleccionistas crearon para uso público o donadas a las administraciones - como es el caso de la colección Pollok-.

Ya en el siglo XVII habíamos asistido a la ruptura del monopolio artístico de las instituciones eclesiásticas y monarquías, pasando el arte a depender también de las grandes familias aristocráticas, que buscaban mostrar su estatus a través de la adquisición de obras - algo ya visto en el Renacimiento - Estas familias tendrían grandes casas y palacios que había que decorar, para ello, necesitaban todo tipo de obras de arte. Estos espacios se abastecerán a través de demanda de toda clase de temática, pero lo más relevante, la nueva dinámica de intercambio de obras artísticas, desarrollándose un comercio artístico de importancia que llegará a alcanzar intercambio internacional. Para escenario de este mercado artístico se crearán puntos de encuentro donde marchantes vendan y compren obras. Del mismo modo, vemos un cambio en la figura del pintor, quien será sometido al mercado, ahora, es el marchante el gran beneficiado del desarrollo del coleccionismo, el artista, por su parte, adquirirá consideración social hasta el punto de convertirse en consejero o mediador artístico de grandes personalidades reales y aristocráticas.

Con la Ilustración asistimos a los grandes museos nacionales. Museos que surgen por las colecciones de las monarquías de cada país. Pero también, museos de carácter específico, como museos de arquitectura, industriales... A partir de este momento, la burguesía comenzará a comprar arte no sólo por su valor estético o artístico, sino por su deseo de mostrar sus riquezas y calidad de vida. Este nuevo siglo 
va a estar marcado por esta burguesía que será la que determine el gusto artístico de la época. Mostrarán orgullosos sus adquisiciones que estarán siempre relacionadas con su estilo de vida, coleccionar arte supondrá una forma de prestigio.

A pesar de esta nueva visión del coleccionismo, continuarán las personalidades que no harán del coleccionismo una simple inversión, sino que adquirirán la obra artística por su pasión por el arte y la historia, como es el caso del barón escocés.

El siglo XIX supondrá un punto de inflexión en el gusto e interés coleccionista europeo. España empieza a despertar el interés de los eruditos anglosajones por la visión romántica que se crea sobre el país, una visión folklórica y de tintes exóticos gracias a la literatura que provocará que las tierras íberas sean incluidas en el Grand Tour, y comiencen a llegar jóvenes británicos y un gran número de marchantes de arte a establecerse en España. A esto hay que añadirle que, durante dicho siglo, se comienzan a escribir en las tierras inglesas textos sobre el arte barroco español, y teniendo en cuenta que los mercados italianos y flamencos se habían explotado hasta la saciedad durante los siglos anteriores, en España se ve una nueva oportunidad de productos y nuevos recursos para ampliar sus colecciones. Sin dejar a un lado que la Guerra de la Independencia supondrá un acercamiento de los británicos hacia España. Pese a todos estos factores, no hay que olvidar que será en París donde se geste la moda por lo español, gracias a la creación de la Galería Española de Luis Felipe en 1838, con su consecuente exposición de obras del Siglo de Oro. En el cambio de siglo, los principios estéticos sustituirán a los éticos.

Francis Bacon describía el Grand Tour como una formación completa de los jóvenes de clase social alta. La finalidad de cada viaje era empaparse de las características de las cortes, la religión, los monumentos y antigüedades, los ambientes teatrales y los detalles de las costumbres, como fiestas, bodas, funerales o ejecuciones ${ }^{2}$. Hasta el momento España había sido excluida de esta necesidad de expandir fronteras y conocer culturas y países por la visión "negra" que se tenía de ella. Con instituciones como la Inquisición, abolida en la década de los treinta, esa visión del fanatismo religioso entre la población o sus costumbres crueles y bárbaras como las

2 F. BACON, «Of Travel», The Essays, Pantianos Classics, 2016. 
corridas de toros, convertían el país en un lugar que nada podía aportar a la formación ilustrada de los jóvenes de alta clase. Así, en aquel momento, con España como nueva parada en estos viajes y la llegada de las tropas de Wellington y Moore con motivo de la Guerra de la Independencia, comienzan las publicaciones de cartas y diarios militares y de intereses culturales. Destacar, por ejemplo, Viajes por Portugaly España de Richard Twiss o El manual para viajeros en España y lectores en casa de Richard Ford $^{3}$.En su obra Viajeros y eruditos. Los europeos ante la pintura española del Siglo de Oro, García Felguera hace referencia al cambio que acontece en la literatura británica, donde se dejan a un lado las meras descripciones costumbristas para dar paso a relatos de viaje y ensayos de arte con tintes críticos ${ }^{4}$.

Richard Ford, con la obra anteriormente nombrada y algunas otras, como el texto sobre Velázquez que sería publicado en la Penny Cyclopadiae ${ }^{5}$, sería uno de los encargados de dar prestigio a la pintura española y popularizar el estilo español entre la aristocracia y la alta burguesía de Reino Unido. Éste, que vivió en Andalucía durante un tiempo, tomó el papel de marchante de arte además de coleccionista. De hecho, Ford y Stirling terminaron por ser grandes amigos durante las últimas etapas de la preparación de los Anales. A pesar de que cuando Stirling envió un extracto de su manuscrito a John Murray — editor del manual publicado por Ford-, éste se lo remitió al propio Ford y su crítica fue realmente dura, tachándolo de dross and commonplace. Ford se quejaba de que Stirling no hubiera captado la filosofía del arte español, además de criticar el gran número de artistas españoles nombrados, que no eran en absoluto conocidos en Reino Unido, lo que supondría una incomprensión parcial de su obra ${ }^{6}$.La relación entre ambos cambió cuando hacia finales de 1846 el propio Stirling contactara personalmente con Ford para pedirle una revisión de la obra. En esta ocasión, la crítica de Ford fue positiva, éste estuvo

\footnotetext{
3 La obra de Twiss fue publicada en 1775 bajo el título Travels through Portugal and Spain, existen dos ediciones en español de Cátedra publicadas en 1999: Viaje por Portugal en 1772 y Viaje por España en 1773; La obra de Ford fue publicada en 1845 bajo el título $A$ handbook for travellers in Spain. La traducción española de la editorial Turner es de 2008.

4 Véase M.GARCÍA FELGUERA, Viajerosyeruditos. Los europeos antelapintura españoladel Siglode Oro, Alianza Forma, Madrid, 1991.

5 Promovida por el canciller lord Henry Brougham como proyecto de la Sociedad para la Difusión del Conocimiento Útil que fundó en 1832 una vez retirado de la política. Véase Boletín de la Real Academia de la Historia, Tomo CLXXXII, $\mathrm{n}^{\circ}$ II, 1985, pp. 233-234.

6 La primera crítica hacia el manuscrito de Stirling por parte de Ford fue tacharlo de escoria y vulgar. Carta de Ford a Murray, el 11 de febrero de 1845. En los Archivos de John Murray, Londres, número 88, en H. MACARTNEY, "Sir William Stirling Maxwell: Scholar of Spanish Art", Espacio, Tiempo y Forma, Serie VII, n 12, 1999, pp. 287-316.
} 
encantado con el hecho de formar parte de las últimas etapas de preparación de los Anales, citando a Macartney, perhaps his criticism in 1845 were influenced by the fact he had not been consulted at that stage [quizás su crítica en 1845 estuvo influenciada por el hecho de no haber sido consultado en ese momento] $]^{7}$

Así, tanto los manuales y diarios de los viajeros, que recogían en la mayor parte de los casos descripciones del arte español, como los textos propiamente dedicados a la pintura fueron alentando a los británicos hacia un aprecio y una adquisición para sus colecciones de arte, especialmente del Siglo de Oro en un principio, pero que más tarde será también de obra contemporánea. El gusto inglés sería también influenciado por la llegada a España de artistas británicos como David Wilkie, David Roberts o John Lewis ${ }^{8}$.

Además de esta reivindicación en el gusto por lo español, el panorama político y social hizo posible la adquisición de obras españolas a bajo precio. Nos encontramos en un periodo donde la invasión napoleónica y la consiguiente Guerra de Independencia daba lugar a un panorama pésimo en lo que a protección artística se refería, así, marchantes como el escocés William Buchanan aprovecharon la situación tan caótica para adquirir obras de arte del Siglo de las Luces a escaso precio, abasteciendo así el mercado con la clientela inglesa. Situación que pronto imitarían otros marchantes ${ }^{9}$.

Ciudades como Sevilla, Cádiz o Madrid fueron escenario de un enorme expolio por parte de estos comerciantes que vieron una oportunidad para adquirir arte español, ahora tan de moda, satisfaciendo así las necesidades aristocráticas inglesas. A pesar de esta oleada de británicos en búsqueda de ofertas artísticas, la situación política daba ventaja a los marchantes franceses por encima de los ingleses, sin olvidar el "mercado negro" fomentado por los soldados, quienes malvendían piezas de calidad, desvirtuando el valor de las cotizaciones que se llevaba a cabo en el mercado profesio-

\footnotetext{
$7 \quad$ Ibídem, p. 296.

8 F.HASKELL, Rediscoveries in Art. Some aspects of taste, fashion and collecting in England and France, Cornell University Print, Oxford, 1980.

9 H. BRIGSTOCKE, William Buchanan and the 19th Century Art Trade: 100 letters to his agents in London and Italy, Paul Mellon Centre for Studies in British Art, Londres, 1982.
} 
nal ${ }^{10}$.Vemos cómo muchas ciudades españolas como Sevilla fueron esquilmadas por las tropas británicas y francesas, lo que influyó en gran medida al arte. El mercado artístico no fue sólo cosa de particulares, las subastas en galerías como Christie's fueron recurrentes, donde a partir de la primera década del siglo XIX, los cuadros que provenían de España fueron aumentando cada vez más, a pesar de que todavía en el Reino Unido el arte español es un desconocido casi en su totalidad, por lo que lotes con piezas que hoy consideramos obras maestras fueron vendidas por preciosirrisorios. Buchanan en su obra describía los pocos escrúpulos de las tropas francesas para hacerse con obras españolas de iglesias o monasterios, así, durante las dos primeras décadas del siglo habrá subastas de obras propiedad de miembros de los ejércitos, tanto inglés como francés, colecciones que habían reunido durante la ocupación de la península. Para hacernos una idea y atendiendo al British Customs Departament, hacia 1810 la pintura española en el mercado británico suponía un 60\% del total del arte con el que se comerciaba ${ }^{11}$.

El propio Stirling, en sus Anales fue capaz de criticar la dispersión del arte español fuera de España a causa de los expolios franceses y las compras de coleccionistas y marchantes franceses y británicos. Si bien su actitud era ambivalente - lo que resulta lógico, teniendo en cuenta que él sería partícipe de esta situación -, por un lado le agradaba la valoración internacional que se pretendía lograr de la escuela española con esta dispersión, pero por otro lado, apelaba a su raciocinio de historiógrafo, revelando lo que suponía una pérdida por completo del contexto original, así como la total dispersión de series de obras relevantes ${ }^{12}$.

Nos encontramos en un momento en el que existe una creciente euforia hacia lo español en el mercado, destacando a Murillo, Velázquez, Zurbarán o Coello. A pesar de ello, Murillo sería el verdaderamente aclamado entre el público británico, mientras que Velázquez sería apreciado entre los círculos eruditos, lo que explica las

\footnotetext{
10 W. BUCHANAN, Memoirs of painting, R. Ackerman, Londres, 1824.

11 Véase A.M. FERNÁNDEZ, "Pintura y comercio. Las relaciones anglo-españolas en el siglo XIX”, Norba-Arte XVIII-XIX, 1998-1999, especialmente pp. 235-236; Los estudios del British Customs Departament están recogidos en B. FREDERICKSEN, The index of paintings sold in the British Isles during the Nineteenth Century, Getty Publications, Los Ángeles, 2006.

12 W. STIRLING-MAXWELL, Annals of Artists of Spain, 1848, pp. 49-51; También recogido en H. MACARTNEY, "La colección de arte español formada por Sir William Stirling Maxwell" en Colecciones, expolio, museos y mercado artístico en España en los siglos XVIII y XIX, Editorial Universitaria Ramón Areces, Madrid, 2011, p. 243.
} 
obras teóricas de algunos intelectuales, como el propio Stirling ${ }^{13}$. Pese a esta revolu- ción en las élites británicas, el recibimiento de los artistas españoles entre el público general era prácticamente inexistente e incluso en ocasiones hostil, Fernández expo- ne el caso de un miembro del Comité de la National Gallery, que en 1853 afirmaba que la escuela española podía considerarse, más o menos, como una corrupción de las queridas escuelas italianas, y lo más significativo fue que esta sentencia no encontró apenas opo- sición entre el resto de la comisión... ${ }^{14}$ Esto implicará una situación de descontextuali- zación total del arte, que pasará de colecciones españolas a colecciones europeas que apenas conocían a los artistas ni comprendían el contexto artístico de las obras en la mayoría de los casos. Pero debido a la situación política, ante el prestigio que suponía tener en las colecciones privadas obra artística española, esta descontextualización o incomprensión no supondrá un inconveniente para que el mercado artístico siguiera funcionando con dirección Reino Unido.

No es posible hablar y entender la colección Pollok sin previamente analizar la colección Stirling-Maxwell. Se puede decir, pues, que la colección emplazada hoy en Glasgow es una parte de lo que fue una colección más amplia, reunida por elhistoriógrafo y barón escocés William Stirling Maxwell. Stirling llegó a reunir una de las colecciones privadas más excepcionales de su tiempo en todo Reino Unido como ya hemos podido percibir anteriormente, en la cual situaba como base principal la pintura española. A pesar de que su interés no estaba orientado únicamente hacia lo español, el arte y la literatura que se había desarrollado en la península despertaba en el escocés la expectación propia de un intelecto curioso e inquieto.

Para mediados de los años cincuenta, su colección estaría compuesta por alrededor de ciento treinta pinturas al óleo, unos trescientos dibujos, las grandes series de aguafuertes de Goya; grabados y estampas a partir de cuados de maestros españoles como Velázquez o Murillo; así como una inmensa colección bibliográfica, formada por unos dos mil libros de emblemas y fiestas y los más importantes tratados de arte del Siglo de Oro español ${ }^{15}$.

\footnotetext{
13 W. STIRLING-MAXWELL, Velázquez and his works, John W. Parker and Son, Londres, 1855.

A.M. FERNÁNDEZ, op. cit., p. 237.

D. WESTON, Sir William Stirling Maxwell and the European Emblem, University Library, Glasgow, 1987; H. MACARTNEY, "La colección de arte español formada por Sir William Stirling Maxwell” en Colecciones, expolio, museos y mercado artístico en España en los siglos XVIII y XIX, Editorial Universitaria Ramón Areces, Madrid, 2011, p. 237.
} 
No hay mejor forma de entender a Stirling Maxwell y su colección que aludiendo a una de las citas más célebres de la obra de Jiménez y Mack, el coleccionismo es una manera de ordenar el mundo y una forma de expresión de la propiapersonalidad ${ }^{16}$. La búsqueda por satisfacer sus intereses históricos y darlos a conocer en su mundo, tan alejado del español, llevará al escocés a adquirir un extenso número de muestras artísticas y literarias para conformar una colección llamada a ser la colección privada más relevante del siglo XIX en Escocia y todo Reino Unido.

La colección Stirling Maxwell comenzó a gestarse en las primeras décadas del siglo XIX. Al cumplir los treinta años el escocés contaba con la capacidad intelectual y económica que le permitieron acceder a las mejores subastas de toda Europa, de hecho, tras la muerte de su padre en 1847, heredó Keir House y todas las tierras colindantes, lo que le convirtió en uno de los terratenientes más ricos de toda Gran Bretaña. Su posibilidad y afición por los viajes le permitieron establecer relaciones que le posibilitaron la adquisición de las numerosas piezas que compondrían su colección. Tuvo la opción de pujar e incluso comprar algunas obras que previamente había alabado por su importancia artística o histórica en el proceso de elaboración de sus Anales, como, por ejemplo, el caso del retrato que compra en París ese mismo año, del que Stirling sospechaba que podría tratarse del Retrato de Isabel de Malcampo pintado por Murillo, obra que conocía a través de los escritos de CeánBermúdez ${ }^{17}$.

Respecto al arte español, en noviembre de 1841 pisaría la península por primera vez, visitando Cádiz y Sevilla. Esa primera visita duró únicamente una semana, de la cual sólo un día lo utilizaría para descubrir Sevilla, como registra en su cuaderno de viaje. En una carta a su hermana describía la catedral de la ciudad hispalense como the finest Gothic Church in the world ${ }^{18}$. Un año después, regresaría a España y la visitaría durante un periodo de dos meses. Durante ese periodo estuvo en Madrid y Andalucía, y en el trayecto de un lugar a otro, visitaría Toledo, donde admiraría la

\footnotetext{
16 M.D. JIMÉNEZ BLANCO y C. MACK, Buscadores de belleza. Historias de los grandes coleccionistas de arte, Ariel, Barcelona, 2007.

17 H. MACARTNEY, "La colección de arte español... op. cit.", pp. 241-242, donde nombra la nota de Stirling transcrita en el catálogo de Caw, 1936 - quien pensaba que si bien no era la obra original, debía tratarse de una copia de ella, por las características descritas por Ceán -, así como la Carta de Ceán Bermúdez de 1806 donde se habla de dicho cuadro de Murillo.

18 En Papers of Stirling of Keir, referencia T-SK 29/1/52, Archivo de la ciudad de Glasgow (en adelante Referencia T-SK y su correspondiente número de archivo).
} 
obra del Greco. Su tercer viaje tuvo lugar en abril de 1845, visitó Valencia, Madrid y la población de Illescas en Toledo ${ }^{19}$, y fue en ese periodo cuando estableció amistad con diferentes personajes ilustrados de la época, como el escritor Bartolomé José Gallardo o el pintor y coleccionista Valentín Carderera. A través de ellos adquirió gran parte de la obra española que conformaba su colección, este último, por ejemplo, fue el mediador para la adquisición de la mayoría de la obra de Goya que el escocés atesoró, entre ellos, las pruebas preparatorias de Los Disparates y de Los Desastres de la Guerra $^{20}$. Carderera, quien tenía contacto con el nieto de Goya, se convertiría en la fuente idónea para la compra-venta de obra del artista. Su último viaje a España data de 1849, donde visitó Andalucía y Madrid.

Así, podemos afirmar que las décadas de 1840 y 1850 supondrían las más activas en su labor como coleccionista e historiógrafo, pero esencialmente en referencia a España. Si bien sus contactos con personajes relevantes en la cultura decimonónica del momento le dio la oportunidad de adquirir obras en la propia península, serán en las relevantes subastas de las capitales europeas, como Londres o París, las que le permitieron ampliar de manera considerable su colección. A destacar la venta de la colección de Sir John Brackenbury, ex cónsul británico en Cádiz, en 1848; la del General John Meade, ex cónsul general en Madrid, en 1851; la venta de la colección del Mariscal Soult en 1852; o las subastas de la Galería Española de Luis Felipe y la colección de Frank Hall Standish, legada al rey francés, en 1853.

Atendiendo a sus cuadernos personales, se piensa que las primeras compras de arte español datan de 1841, cuando encargó al pintor andaluz José Roldán unas copias de obras de Murillo, por el que se sentía un gran aprecio en el mercado inglés ${ }^{21}$. Y al año siguiente adquiriría en Sevilla cuatro pequeños esbozos al óleo de niños jugando pertenecientes al pincel de Goya, de los cuales dos pasaron a formar parte de la colección Pollok.

\footnotetext{
19 Conocemos sus itinerarios de viaje gracias a sus cuadernos, referencia T-SK28/9-11.

20 Las primeras se encuentran en la colección Pollok, los segundos fueron adquiridos por el Museo de Bellas Artes de Boston.

21 E. VALDIVIESO, Historia de la pintura sevillana, Guadalquivir ediciones, Sevilla, 2002.
} 
De su visita a Sevilla del año 1845 se tiene constancia de la compra de dos bodegones atribuidos a Velázquez, a través del marchante José de Olmedo ${ }^{22}$.De ellos, el Bodegón de fruta y cálices, con atribución a la escuela española, permanece en la colección Pollok, el otro, Bodegón con pescado es atribuido en la actualidad al círculo de Alejandro Loarte y fue vendido en subasta de Christie's el 14 de diciembre de 1990 y adquirido por un particular estadounidense para su colección, por lo que no se tiene más información sobre él. Ese mismo año sería el que entablaría amistad con Bartolomé José Gallardo, por lo que, además de las obras literarias ya mencionadas, adquiriría el primero de sus ejemplares de Los Caprichos de Goya, serie que actualmente se encuentran en la Universidad de Glasgow como parte de una donación de los descendientes del escocés. Su amistad con Valentín Carderera le llevó a la adquisición de las obras de Goya ya mencionadas, la mayoría de sus aguafuertes y las pruebas raras de los Disparates que hoy forman parte de la colección Pollok ${ }^{23}$.

Cuando visitó Valencia en 1849 compró a través del marchante Pedro Pérez, apodado "el peluquero" un Retrato de Palomino por Juan Bautista Simó, que fue vendido posteriormente y hoy se encuentra en una colección particular en México. Esta compra se debió a su valor como documento, firmado y fechado en $1726^{24}$, el propio Stirling escribió en un trozo de papel al dorso del cuadro que había comprado el retrato por ser el único quejamás he vistou oído hablar de Palomino ${ }^{25}$.Además, también reflejó la incompatibilidad entre la fecha del cuadro y la de la muerte de su supuesto autor nueve años antes, como había leído en el Diccionario de Ceán Bermúdez. Este retrato sería vendido en la subasta de Christie's que tuvo lugar en 1990.

Pero no toda la obra española fue adquirida en España, como ya hemos mencionado anteriormente, en las décadas de los cuarenta y los cincuentas tuvieron lugar en las principales ciudades europeas subastas de grandes colecciones, en su mayoría fruto del periodo napoleónico, lo que, si bien Stirling fue capaz de criticar, por el expolio llevado a cabo en España así como la resultante descontextualización de las obras artísticas, no dejó escapar dichas oportunidades. De igual modo, estableció

\footnotetext{
22 Referencia T-SK 28/11.

23 H. BRIGSTOKE, "El descubrimiento del arte español en Gran Bretaña", en Z. VÉLIZ (dir.), En torno a Velázquez. Pintura española del siglo de oro, cat. exp., Apelles, Londres, 1999, p. 14.

24 H. MACARTNEY, "La colección de arte... op. cit.", p. 242.

25 Nota transcrita en el catálogo de CAW que MACARTNEY recoge en ibídem.
} 
relaciones con diferentes marchantes que le permitieron adquirir tanto obra literaria como pictórica. Destacar, por ejemplo, la compra en el año 1847 del retrato Dama con una rosa en París, a través del librero y editor español en la capital francesa, Vicente Salvà. Dicha obra se encuentra en la actualidad en una colección privada en Escocia. La motivación que llevó a Stirling a adquirir dicha obra no sería otra que la idea de que podía tratarse del Retrato de Isabel de Malcampo, esposa del comerciante flamenco Nicolás Omazur pintado por Murillo que hoy podemos ver en el Museo del Prado ${ }^{26}$, lo que demuestra el exhaustivo conocimiento que tenía de la escuela sevillana, gracias sobre todo, a la obra de Ceán Bermúdez, como menciona el propio coleccionista en la nota al dorso de la obra ${ }^{27}$.

De entre las subastas acontecidas, destacar la de la colección del cónsul Brackenbury tras su muerte, que tuvo lugar en Londres en 1848. Algunas de las obras adquiridas en esta subasta fueron Los desposorios místicos de Santa Catalina de Siena de Zurbarán que en la actualidad se encuentra en el Meadows Museum de Dallas; un lienzo de grandes medidas de Juan del Castillo, maestro de Murillo según Palomino, de Santo Domingo en Soriano, procedente del convento de Monte Sión de Sevilla y del que Ceán habla en su diccionario, lo que una vez más muestra la importancia que el escocés le daba al historiador español ${ }^{28}$. Dicho cuadro fue vendido en la subasta de 1990; dos obras de Goya de pequeñas dimensiones, que al estar mencionadas en su cuaderno como "Caprichos o Caricaturas" no se sabe con exactitud de qué tipo de técnica se trataba, Macartney establece la posibilidad de que se tratara de dos miniaturas sobre marfil que estaban en la colección Stirling; una pequeña escultura policromada de una Inmaculada de Alonso Cano, tratándose estas adquisiciones de las pocas en una técnica diferente a la pintura o el dibujo ${ }^{29}$; además del lienzo de La Serrana de Murillo $^{30}$, una obra temprana del sevillano de la Virgen con el niño y San Juanito que el escocés ya conocía antes de adquirirla, probablemente a través del marchante y también pintor José María Escacena, quien le vendió el cuadro a Brackenbury tras adquirirlo del convento de Madre de Dios de Sevilla en el año 1838, con quien tenía

\footnotetext{
26 Véase https://www.museodelprado.es/coleccion/obra-de-arte/nicolas-omazur/83b32eaf-4999-4ba3-811d-501fdcf6b3e7

27 Isupposed it might be the portrait of Doña Isabel de Malcampo painted by Murillo which [...] is described by Ceán Bermúdez in his carta, p. 105. If not the original it is probably a copy of that picture. Véase nota al pie 17.

28 J.A. CEÁN BERMÚDEZ, Diccionario de las Bellas Artes en España, Madrid, 1800, vol. I, p. 288.

29 H. MACARTNEY, "La colección de arte... op. cit.”, p. 243.

30 Esta obra debe su nombre al lienzo blanco con una esquina en verde y rojo y una franja como las moriscas que tejían los campesinos en la Serranía del Condado de Niebla, en ibídem,p. 245.
} 
contacto por ser el que se encargaba de venderle las pieles con las que Stirling encuadernaba los libros de su colección ${ }^{31}$.

Entrado la mitad del siglo, destacar la subasta del general Meade en 1851, donde Stirling adquirió su primera obra del Greco, Dama con una flor en el pelo, que hoy se encuentra en una colección privada en Estados Unidos; o los Retratos de Felipe IV y Ana de Austria de Sánchez Coello que podemos ver en la colección Pollok.

En 1853 tuvieron lugar en Londres las subastas de la Galería Española del rey Luis Felipe y la de la colección de Frank Hall Standish, donde Stirling adquirió obras sobre las que había leído e investigado durante la preparación de los Anales, visitando ambas colecciones en París. En estas subastas el historiógrafo compró casi una veintena de obras, entre ellas cuatro grecos, de los cuales dos se encuentran en la colección Pollok, La dama del armiño y El retrato de hombre desconocido; y la Adoración del nombre de Jesús, que hoy podemos visitar en la National Gallery de Londres, y el retrato inacabado de Pompeo Leoni esculpiendo un busto de Felipe II, obra cuya atribución ha sido discutida, habiendo puesto sobre la mesa la posible autoría de Sofonisba Anguissola ${ }^{32}$. También adquirió en estas ventas otras obras relevantes como el Autorretrato de Vicente Carducho o la Primera labor de Adán y Eva o la Piedad de Luis de Morales, todas ellas en la colección Pollok, entre otras ${ }^{33}$.

Con todo, y una vez habiendo realizado un acercamiento a la colección original Stirling Maxwell, podemos afirmar que la dispersión de dicha colección comenzó tras su muerte, en el año 1878, una vez que legó sus bienes a sus descendientes. La colección fue repartida entre sus dos hijos. Diez años después, una vez alcanzada la mayoría de edad, el hijo mayor, Sir John Stirling Maxwell, trasladó su herencia a la casa familiar por parte materna, una casa afincada en Pollok Park, al sur de Glasgow.

\footnotetext{
31 Ibídem; B. NAVARRETE PRIETO y A.E. PÉREZ SÁNCHEZ, El joven Murillo, Museo de Bellas Artes, Bilbao, 2009, pp. 302-305.

32 C. MARINAS, "La Galería Española del Rey Luis-Felipe", en Academia: Boletín de la Real Academia de Bellas Artes de San Fernando, 1983, № 57, pp. 127-152.

33 Para más información sobre las obras adquiridas en estas subastas véase H. MACARTNEY, "La colección de arte español... op. cit.”, pp. 248-257; sobre la colección en particular del rey Luis Felipe véase la tesis doctoral de Cristina Marinas de la Universidad de la Sorbona.
} 
Esta colección, que es la que nos ocupa esta investigación, permanece en el lugar casi en su totalidad ciento treinta años después, estaba compuesta por unos cincuenta cuadros españoles, así como la mayoría de los dibujos y grabados de dicha escuela y una gran parte de la biblioteca.

Emplazado al suroeste, a las afueras de la ciudad de Glasgow, se encuentra el Pollok Country Park, un espacio natural de unas 146 hectáreas de superficie donde la familia Maxwell, perteneciente a la alta aristocracia escocesa, se había asentado desde el siglo XIII, concretamente desde $1270^{34}$. Pollock House fue diseñada hacia la primera mitad del siglo XVIII, si bien no hay documentos concluyentes sobre su autoría, se pensó para ser diseñada por el arquitecto William Adam,el arquitecto universal en Escocia $^{35}$.

Por su parte, el hijo menor, Archibald, se quedaba en Keir, la casa donde su familia había vivido y donde parte de la colección estuvo colgada durante la vida de Sir William, con la otra parte de la herencia de su padre, compuesta por unas ochenta obras españolas.Éste se desharía de la colección entrado el siglo XX.

De la colección de arte inicial que el noveno barón Maxwell atesoró no existe un catálogo completo, por lo que es complicado ubicar con exactitud el paradero, así como el contenido de las piezas artísticas que contenía. Por otro lado, conocemos que los dibujos españoles de la colección Pollok fueron vendidos en Londres, en Important Old Master Drawings, subasta de Sotheby's, los días 15 y 16 de febrero del año 1921. Muchos de ellos se encuentran en la actualidad en la Colección Witt; en el Courtauld Institute de Londres; en la Colección Apelles de la misma ciudad; en la Hispanic Society of America de Nueva York; así como en colecciones particulares.

\footnotetext{
H Para la genealogía de la familia véase W.FRASER, The Stirlings of Keir and their Family Papers, Privately printed, Edimburgo, 1858; P. MONTAGUE-SMITH, Debrett's Peerage \& Baronetage, Debrett's Peerage Limited, Londres, 2008; C. WATERSTON and A. MACMILLAN SHEARER, Former Fellows of the Royal Society of Edinburgh, 1783-2002, Part Two, The Royal Society publications, Edimburgo, 2006, p. 635.

3 William Adam (1689-1748). Comenzó su labor como arquitecto aproximadamente hacia el año 1715, pero fue a partir de 1720 cuando fue reconocido por diversas instituciones, así como por sus contemporáneos como el arquitecto líder de su generación, recibiendo encargos en toda Escocia. El término Universal Architect fue utilizado por primera vez por el ilustrado escocés John Clerk de Eldin para describir a Adam, en la biografía del hijo del arquitecto, Robert Adam.

Para la cronología de construcción y restauraciones posteriores de la casa véase la entrada de Pollok House en la web Scottish Architects http://scottisharchitects.org.uk/building_full.php?id=200283
} 
Las principales subastas de venta de la colección inicial además de la ya nombrada, tuvieron lugar pasada la mitad del siglo XX, destacando Old Master Paintings, subasta de Sotheby's que tuvo lugar en Londres el 3 de julio de 1963 y Old Master Paintings, subasta de Christie's que tuvo lugar en la misma ciudad el 14 de diciembre de 1990.

La dispersión en colecciones de instituciones públicas y colecciones privadas del legado Stirling a su hijo menor fue total; por su parte, el primogénito, John, quiso mantener la colección paterna, exhibiéndola en Pollok. A pesar de que hoy podamos ver esta colección hay que ser conscientes de los motivos que llevaron al décimo barón a mantener y exhibir esta colección pictórica. Nos encontramos ante un caso de coleccionismo como forma de prestigio y ostentación, y una muestra de erudición, si bien éste nunca se preocupó por ampliar la colección, únicamente mantener las obras que ya tenía, pero en especial, aquellas de gran importancia por su artista o procedencia, mientras que las series de dibujos y grabados fueron en su mayoría vendidos, al igual que gran parte de la colección de $\operatorname{libros}^{36}$, lo que nos habla de una falta de comprensión y pasión hacia aquellas piezas de arte que conformaban la colección paterna y que llevaron a sir William a adquirirlas.

Fueran los que fueren los motivos que llevaron al descendiente de Stirling a mantener su legado, su decisión supuso que hoy tengamos al alcance una de las colecciones privadas imprescindibles del siglo XIX en lo que a difusión del arte español en Reino Unido respecta. Si bien hay que ser consciente de que, casi dos siglos después de la formación de la colección, la necesidad de la contextualización de la formación de la colección se convierte en ineludible para poder entender cada una de las obras pictóricas que encontramos en las paredes de Pollok House, qué circunstancias se dieron para que retratos de la monarquía española o las patronas de la ciudad de Sevilla estén en la sala de estar de una casa solariega a las afueras de Glasgow, y todas las intenciones de difundir la historia y el arte de un país que en aquel momento era un total desconocido.

\footnotetext{
3 La mayoría de los libros fueron vendidos en Christie's en la subasta Important Printed Books and an illuminated manuscript: the property of the trustees of the late Sir John Stirling-Maxwell que tuvo lugar entre el 20 y el 23 de mayo de 1958.
} 
La importancia de esta colección de arte español reside en las obras que forman parte de ella, por la relevancia de algunas de las piezas en sí, así como sus autores, pero también por la adquisición de obras como testimonio del contexto histórico artístico en el que se hicieron, así como en el que secompraron.

Una obra de arte habla, sin lugar a dudas, del momento de la historia en la que está siendo concebida, habla también de su autor, de su comitente; pero una obra de arte habla también del coleccionista que la adquiere en una subasta, siglos después, y también del público, que, por unas razones u otras, acaba contemplándola. Tomando las palabras que una vez escuché en una conferencia de Calvo Serraller, una colección es la afirmación de una autobiografía resumida.

La colección Pollok estaba formada por cincuenta y cuatro obras españolas y la mayoría de los dibujos de la colección inicial cuando el primogénito, sir John Stirling Maxwell, se traslada a Pollok House en 1888. Tras la venta de los dibujos en 1921, la colección está compuesta, en la actualidad, por los más de cincuenta óleos.

Si bien nunca se publicó un catálogo de la colección entera a pesar de la costumbre que los coleccionistas adquirieron desde finales del siglo XVIII en el Reino Unido, como pone de manifiesto la magna obra Treasures of Art in Great Britain o Galleries and Cabinets of Art in Great Britain, ambas del alemán Gustav Waagen, sir James Caw, primer director de la National Gallery de Escocia, editó en 1936 un catálogo de los cuadros de Pollok House, en calidad de amigo de sir John Stirling. Antes de este intento de inventario, el propio coleccionista procuró establecer un método de catalogación a través de la colocación al dorso de cada obra un papel en el que apuntaba información sobre la procedencia y la adquisición del cuadro, añadiendo a veces notas sobre su opinión respecto a atribuciones. Si bien, muy probablemente, Stirling habría guardado copias de estos documentos para un catálogo propio ${ }^{37}$, no han llegado a nuestros_días, tal vez como resultado de los traslados de las obras, al igual que

\footnotetext{
37 Se conoce la publicación en edición privada de catálogos de parte de su biblioteca, así como un catálogo de estampas de su colección. W. STIRLING, Essay towards a Collection of Books Relating to Proverbs, Ebmlems, Apopthegms, Eitaphs and Ana, Londres, 1850 y 1860; W. STIRLING, Essay towards a Collection of Books Relating to the Arts of Design, Londres, 1860; W. STIRLING, Essay towards a Catalogue of Prints Engraved from the Works of Velazquez and Murillo, Londres, 1873. Todo recogido en H. MACARTNEY, "La colección de arte español formada por Sir William Stirling Maxwell" en Colecciones, expolio, museos y mercado artístico en España en los siglos XVIII X XIX, Editorial Universitaria Ramón Areces, Madrid, 2011, p. 238.
} 
han desaparecido casi en su totalidad los papeles que estaban pegados a los cuadros, por el mismo motivo, así como por los cambios de marco o sucesivos entelados ${ }^{38}$.

La colección consta hoy, tras la venta de los dibujos, con el mismo número de óleos que contaba en el momento del traslado a Pollok House por parte de sir John. Se trata entonces de cincuenta y cuatro cuadros de los cuales aproximadamente treinta y cinco eran de escuela madrileña, de autores de relevancia como Velázquez o su taller o Goya, pero también de atribuciones o copias de retratos de corte. De escuela andaluza se pueden identificar once cuadros, nueve de ellos de autores sevillanos y dos granadinos, entre los que cabe destacar a Murillo en Sevilla y la obra de Alonso Cano en Granada. De la colección cabe destacar dos de los tres lienzos de escuela toledana, cuyo autor es El Greco, si bien La dama del armiño ha suscitado discusión entre los expertos- y sigue a día de hoy -, hay quien lo ha atribuido posteriormente a Sofonisba Anguissola. Aunque hay que tener en cuenta que, pese a los posteriores cambios de autoría, la atribución que se le daba a la obra en el momento de la compra - y también las sospechas de autoría que el propio Stirling tenía para adquirir muchas de ellas -. En este caso específico, Maxwell compró esta obra como un Greco tras haber quedado fascinado al verla cuando se exhibía en el Louvre, como parte de la colección de la Galería española del rey Luis Felipe de Francia. El título que recibía la obra en el catálogo de esta colección era el de La hija del pintor, si bien, curiosamente, el pintor nunca tuvo una hija.

Completan la colección obras de escuela castellana, valenciana o extremeña, destacando, por ejemplo, la Piedad de Luis Morales el Divino, así como algunas otras de autor desconocido que se consideraban de escuela española o la posibilidad de ser de escuela flamenca o italiana.

La colección, desde su adquisición, estuvo expuesta en las casas pertenecientes a la familia. Cuando Stirling vivía, la colección se exponía en Keir, una casa solariega ubicada en Dunblane, al norte de Glasgow, que el escocés heredó de su padre en 1847 y que posteriormente restauraría para acoger la gran biblioteca que formó ${ }^{39}$; y en Mayfair, Londres, donde el barón compró una casa tras entrar a formar parte de

\footnotetext{
$38 \quad$ Ibídem.

39 H. MACARTNEY, «La colección Stirling Maxwell en Pollok House, Glasgow» en Goya, 2002, n 291, pp. 345-356.
} 
la Cámara de los Comunes ${ }^{40}$. Se conoce de la exposición de las obras en estas casas gracias a los textos de los visitantes. Por su parte, el alemán Gustav Waagen ${ }^{41}$ menciona haber visto algunos de los cuadros en una visita a la casa familiar — no toda la colección, debido a la ausencia del escocés durante su visita, pero también por el traslado de parte de la colección a Londres ya en aquella fecha - en su obra Galleries and Cabinets of Art in Great Britain; por su parte, el conservador de la Scottish National Portrait Gallery, John Gray, visitó el hogar de Stirling en Keir años después de su muerte, recogiendo en Notes on the Treasures at Keir "cómo era la colección y las salas donde estaba colgada" ${ }^{42}$.

Por su parte, la colección Pollok no contempla hoy día un orden museográfico claro, posiblemente la exhibición de las obras se deba a un intento de respetar la ubicación original que sir John les concedió a partir de 1888, cuando se trasladaa Pollok House. Esta inexistencia de un programa museográfico claro otorga a la exhibición un carácter general y una visión de la colección al visitante que lo acerca más al espíritu burgués de colección privada que a la relevancia histórico artística que supone una colección de tales características en la Escocia del sigloXIX.

La falta de un hilo argumental en la disposición de la colección a lo largo de la casa provoca la necesidad de tener algunos conocimientos previos, sino de la colección, del arte en general, para poder distinguir y dar sentido a cada una de las obras. Si bien las pinturas no están ubicadas por escuelas ni temática o cronología, lo que refuerza el efecto de estar observando el hogar de un erudito coleccionista, donde la estética o lo pintoresco de algunos cuadros sobresale sobre cualquier otra cosa. A pesar de ello, podemos asistir a ciertos espacios donde destaca claramente lapintura española entre la británica, la italiana o la flamenca, entre otras. Probablemente la habitación donde más preminencia se le otorga a lo español sea la Sala de Música (Fig. 1) $)^{43}$.

\footnotetext{
$40 \quad$ Fue miembro del Parlamento de Reino Unido por el condado de Perth desde 1852 a 1858.

41 Historiador del Arte alemán relevante en Reino Unido por su obra Los tesoros de Arte en Gran Bretaña, compuesta por cuatro volúmenes publicados en Londres entre 1854 y 1857, y que se convertiría en uno de los más importantes catálogos de colecciones privadas británicas.

42 H. MACARTNEY, «La colección de arte español formada por Sir William Stirling Maxwell» en Colecciones, expolio... op. cit., pp. 238-239.

$43 \quad$ Antes de 1870 esta habitación había sido sala de estar. Y durante la Primera Guerra Mundial, cuando la casa fue utilizada como hospital, a esta sala se le dio uso de habitación de convalecientes.
} 


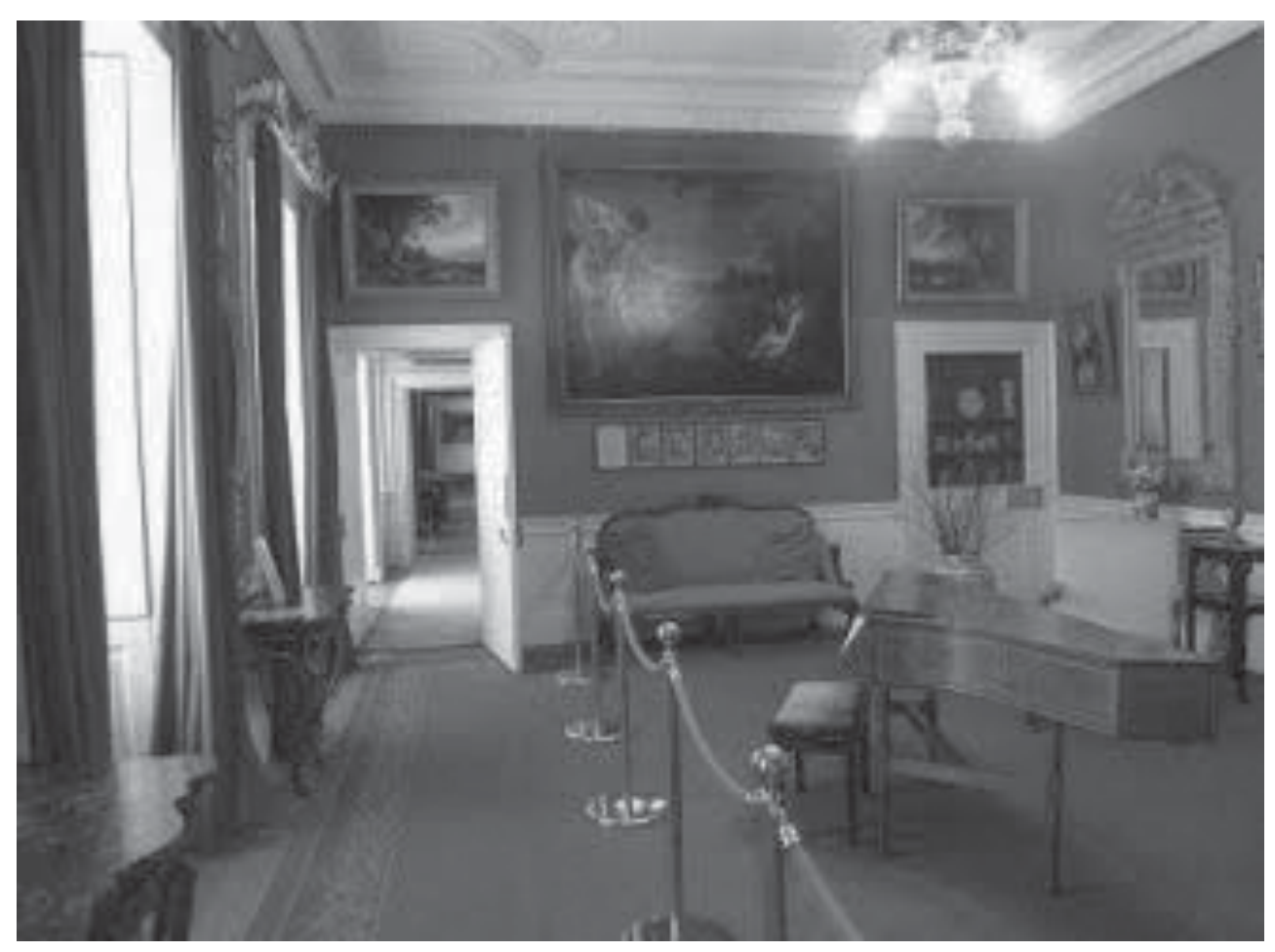

Fig. 1. Vista general de la Sala de Música.

Esta habitación fue convertida en Sala de Música para situar el órgano en el que su mujer tocaba. Lo que más destaca de esta sala es el color de sus paredes, pintadas en un rojo muy fuerte que contrasta con el resto de paredes de la casa, en tonos pasteles. El motivo de esta elección no está del todo claro, hay dos versiones respecto a ello. Por un lado, la pertenencia de sir John al fideicomiso de la colección Wallace de Manchester Square en Londres. En la década de 1910 a 1920 Manchester Square estaba siendo redecorada, utilizando el rojo como color de las paredes, buscandolograr un fuerte contraste con los marcos de las obras ${ }^{44}$, color que el barón trasladaría a su casa. Por otro lado, está la versión opuesta, que fue precisamente John Stirling el que convenció a los otros fideicomisarios de la Wallace Collection para aceptar el color

44 A lo largo del siglo XX, muchas otras galerías vieron la ventaja que suponía los colores fuertes en las paredes para destacar las obras de arte y siguieron el ejemplo de Manchester Square. Sobre la redecoración de los espacios expositivos durante los siglos XIX y XX véase C. BELDA NAVARRO y M.T. MARÍN TORRES, La museología y la historia del arte, EDITUM, Murcia, 2006. 
rojo en la redecoración de Manchester Square. Robert Ferguson, responsable de las propiedades del National Trust for Scotland y estudioso de la casa Pollok es uno de los partidarios de este segundo motivo. Ferguson habla de la revalorización del color rojo en las paredes desde las excavaciones de Pompeya, pero data hacia mediados del siglo XVIII el uso de este color en galerías de arte y librerías por el contraste que permitía resaltar las obras, especialmente los cuadros con sus habituales marcos dorados. Añade que entre finales del siglo XIX y principios del XX estaban poniéndose de moda los papeles pintados en las paredes de las casas, seguía en boga la seda de damasco - sólo en las casas más extravagantes -, pero la decoración pintada era la más popular. Así, teniendo en cuenta la proximidad de la contaminación de los astilleros y las obras de ingeniería de Glasgow, la decoración elegida en Pollok fue la pintura, por mera practicidad. Si bien no se conoce la fecha de la primera vez que se pintó de rojo esta habitación, sí se teoriza que pudo venir por influencia del decorador de Edimburgo David Ramsay, el cual lo puso de moda en Escocia a mediados del siglo XIX ${ }^{45}$.

Si bien la disposición de las obras a lo largo de la casa podría ser en la actualidad meramente aleatoria, se mantiene la idea de que siguen la ubicación inicial entre otras cosas por el estado de la obra de Cristo portando la cruz de Navarrete, cuya esquina inferior derecha mantiene una abrasión causada por el fuego del incendio que tuvo lugar en la Sala de Música en el año $1908^{46}$.

La ausencia del programa museográfico que nombrábamos anteriormente da lugar a la necesidad de una guía para poder comprender el significado y el porqué de la adquisición de cada obra. Ya hablábamos de la necesidad de tener conocimientos previos de arte o de la colección en sí para poder dar sentido a la visita. Al haber procurado respetar la disposición de la casa particular en lugar de haberla acomodado a un estilo museográfico apto para todos los públicos, atendemos a la ausencia de cartelas explicativas - ni siquiera con la información más básica como título, autor y fecha -, únicamente pudiendo encontrar unos pocos paneles titulados Art Focus, en relación a las obras que se consideran de mayor importancia o interés para el público.

\footnotetext{
45 J. MURRAY (ed.), A Guide for Guides, The National Trust for Scotland (inédito), Glasgow.

46 En ese mismo incendio se quemó por completo un lienzo de Henry Raeburn ubicado también en esta habitación. Mi agradecimiento a Joe Murray, Learning Officer de Pollok House, por toda la información inédita prestada sobre la casa y la familia.
} 
La sala alberga seis cuadros españoles en sus paredes. Al entrar nos encontramos, en la pared frente a la puerta la obra de Alonso Cano Las primeras labores de Adán y Eva. El lienzo de más de un metro y medio por dos de tamaño muestra a Adán cavando la tierra mientras Eva hace girar lana con una rueca. La escena muestra un paisaje, también podemos ver a Caín y a Abel de niños. La obra está basada en uno de los grabados de la serie de seis sobre la vida de Adán y Eva del neerlandés Joannes Saenredam basado en la obra del holandés Abraham Bloemaert. Justo debajo de la obra están dispuestos copias de los seis grabados, donde puede verse la casi exactitud con el quinto de ellos, a excepción delpaisaje.

Esta obra fue adquirida por sir William en la subasta del rey Luis Felipe, proveniente de la colección de Frank Hall Standish en mayo de 1853, por la relevancia, no solo por ser una representación excepcional de paisaje en el arte del Siglo de Oro español, sino también por la relación que supone entre la pintura española y los grabados flamencos ${ }^{47}$. Del mismo modo, Ceán Bermúdez nombrará esta obra como perteneciente a una serie realizada por Alonso Cano para el refectorio de la Cartuja de Sevilla, por lo que supondrá un valor añadido para la decisión de Maxwell en la compra de la obra, pues no hay que olvidar el valor bibliográfico y de opinión que el escocés otorgaba al teórico ${ }^{48}$.

En la pared principal de la estancia encontramos el resto de las obras. En el centro, sobre la chimenea, Cristo cargando la cruz de Juan Fernández Navarrete. La obra, de aproximadamente un metro de alto por un metro veinte de ancho, muestra a Cristo en una de las paradas en su camino a la cruz, apoyado sobre una roca tras caerse, Simón el Cirineo le ayuda a sujetar la cruz hasta el Gólgota.

El cuadro es una copia contemporánea de la obra de Cristo y el Cirineo de Tiziano, comprada por Felipe II para su capilla privada en El Escorial. Actualmente, la original se encuentra en El Prado. Así, la adquisición de esta obra muestra el interés que despertaba en Stirling los Habsburgo, el hecho de que el rey eligiera la obra

\footnotetext{
47 Según los documentos, Stirling también poseía el grabado en el que está basada la obra. En B. NAVARRETE PRIETO, La pintura andaluza del siglo XVII y sus fuentes grabadas, Universidad Complutense. Facultad de Geografía e Historia. Dpto. Historia del Arte, Madrid, 1998; y en H. MACARTNEY, "La colección Stirling Maxwell en Pollok House, Glasgow" en Goya, n² 291, 2002, pp. 345-356.

48 J.A. CEÁN BERMÚDEZ, Diccionario de las Bellas Artes en España, Madrid, 1800, vol. 1.
} 
para uso privado, así como la predilección de éste por Navarrete el Mudo darálugar a que el escocés se interese por esta obra en particular, que comprará en la subasta del General Meade en $1857^{49}$.

A la izquierda del espejo de pie que encontramos en esta misma pared, a la izquierda de la chimenea, encontramos la Piedad de Luis Morales el Divino. El lienzo de aproximadamente cincuenta por cuarenta de tamaño representa a la Virgen sosteniendo el cuerpo de Cristo de muerto. El estilo de Morales se considera una simbiosis entre lo italiano, lo flamenco y lo español, lo que no es de extrañar, debido a la importancia artística de Sevilla en aquel momento. El misticismo y la religiosidad de las obras del artista le dieron el sobrenombre de "el Divino", pero cabe destacar más bien su estilo manierista, que algunos sitúa como precedente del Greco en la península, si bien probablemente,nunca llegó a ver sus obras.

La obra fue adquirida en la subasta de Christie's de Luis Felipe en 1853, aunque en el catálogo de dicha subasta hay dos obras que podrían ajustarse a la descripción de la obra, una atribuida a Morales y otra a su escuela, por lo que no conocemos si Stirling adquirió la obra sabiendo que era del propio pintor o solo de su influencia, lo que sí se da por hecho es que la decisión de comprar un cuadro de estas características vino influido por el estilo tan semejante al Greco, al que veremos, será un gran aficionado ${ }^{50}$. La obra es una copia de la que se encuentra en el Museo de Bellas Artes de Bilbao, en la que a los personajes principales les acompañan la Magdalena y San Juan. Se conoce otra de las réplicas, que el Mariscal Soult vendió en subasta un año antes $^{51}$.

Al lado derecho de la chimenea encontramos un cuadro de pequeñas dimensiones donde podemos ver un jardín con algunas figuras, y una escultura clásica en la esquina inferior izquierda. Se trata de El jardín de la Quinta del Prior, obra de escuela española, aunque cuando fue comprada por Stirling estaba atribuida a Velázquez.

\footnotetext{
49 J.A. GAYA NUÑO, La pintura española fuera de España, Espasa-Calpe, Madrid, 1958.

50 J.MURRAY (ed.), A Guide for Guides, The National Trust for Scotland (inédito), Glasgow.

51 I. CANO, "Inventario de la Venta del Mariscal Soult en 1852" en Pintura sevillana y la invasión francesa: la colección del Mariscal Soult, Facultad de Geografía e Historia. Departamento de Historia del Arte, Sevilla, 2015; M. MENA, "Luis de Morales «el Divino». La Piedad del Museo de Bellas Artes de Bilbao" en Boletín Museo de Bellas Artes de Bilbao, $\mathrm{n}^{\circ}$ 5, 2010, pp. 65-108.
} 
Posteriormente se sucedieron las atribuciones, escuela de Velázquez, Martínez del Mazo... También recibió el título de El jardín del Buen Retiro, que posteriormente se corrigió al identificar la escultura que aparece como Sansón y el león de Cristóforo Stati, encargada por el Duque de Lerma, primer ministro de Felipe III, como pareja del grupo escultórico Sansón matando a un filisteo de Giambolonga que Fernando de Médici le había regalado para situarla en su jardín. Cuando el francés rechazó la comisión, fue Stati el encargado de llevar la obra a cabo.

La obra fue, probablemente, comprada en la subasta del ex cónsul británico en Cádiz, el General Meade, en 1851, en Southam, bajo el título A garden scene, with sculpture and landscape de Diego Velázquez ${ }^{52}$.

Bajo esta obra, de dimensiones todavía menores, encontramos el cuadro Paisaje con figuras, atribuido a Juan Bautista Martínez del Mazo. La obra muestra un paisaje descuidado, lleno de maleza. En primer plano se encuentra la figura de una mujer, y en segundo plano, dos figuras e incluso se ha querido ver una tercera esbozada. Se ha hablado de la obra como parte de un grupo de bocetos junto a Two figures before a grassy bank $k^{53}$ para las figuras de una vista del palacio del Buen Retiro, pintada por Diego Velázquez.

Esta obra, si bien no aparece en el catálogo de la venta del General Meade, tiende a relacionarse con ella, por la temática paisajística de escuela madrileña, semejante a la obra anterior ${ }^{54}$.El cuadro fue previamente atribuido a la escuela velazqueña, pues el personaje femenino es prácticamente igual al personaje femenino más cercano a la fuente de la obra La fuente de los Tritones en el jardín de la Isla de Aranjuez de la escuela de Velázquez, que se encuentra hoy en el Museo delPrado ${ }^{55}$.

53 También en la colección de William Stirling que se quedó en Keir, hasta que su hijo Archibal la vendió años después tras heredarla. Hoy se desconoce su ubicación. Curtis, en su catálogo de la obra de Velázquez y Murillo habla de ambos bocetos, en este último menciona a dos personajes apparently making love (p. 28), en relación a la temática del cortejo cortesano que muestra la obra de La fuente de los Tritones en el jardin de la Isla de Aranjuez.

54 C.CURTIS, Velazquez and Murillo: A descriptive and historical catalogue of the works of Don Diego de Silva Velazquez and Bartolome Esteban Murillo, Sampson Low, Marston, Searle and Rivington, Londres, 1883.

$55 \quad$ La obra fue realizada en 1657, formó parte de la colección real. Las atribuciones se han sucedido, desde el propio Velázquez a Martínez del Mazo, hasta la actualidad, que está atribuida a la escuela de Velázquez. Al igual que los bocetos mencionados. Véase https://www.museodelprado.es/coleccion/obra-de-arte/la-fuente-de-los-tritones-en-el-jardin-de-laisla/16d629b1-9797-4a56-8c5b-804dd2f153a7
} 
Cerrando la pared principal, a la derecha del espejo de pie idéntico al ya mencionado, encontramos la obra Santa Justa y Santa Rufina, copia de menores dimensiones de la obra de Murillo que se encuentra en el Museo de Bellas Artes de Sevilla. En el lienzo aparecen las dos patronas de Sevilla sosteniendo una réplica de la Giralda. Aparecen junto a ellas los símbolos del martirio, la palma, así como diferentes piezas de cerámica que aluden a la leyenda de las santas.

A pesar de que no se tiene registro de la adquisición de esta obra, es muy probable que fuera adquirida por el barón en una de sus visitas a España entre $1841 \mathrm{y}$ 1849. O bien que se trate de una de las copias de obras de Murillo que Stirling encargó en 1841 al sevillano José Roldán, tratándose, en este caso, de una de las primeras adquisiciones de obra española del escocés ${ }^{56}$. Si bien se han sucedido las atribuciones, desde Francisco de Zurbarán, pasando por el propio Murillo, hasta la actual atribución a una copia de la original de Murillo, el hecho de que las primeras compras de arte español de sir William fueran de copias de Murillo nos habla del interés de éste por el sevillano, y de que este fuera el motivo que le llevó a comprar este cuadro.

Cerrando la habitación, en la pared opuesta al cuadro de Alonso Cano, encontramos una obra de grandes dimensiones, de más de metro y medio de alto por dos metros de ancho, atribuida al madrileño Antonio de Pereda y Salgado. Dentro de su temática recurrente de alegorías, esta obra, similar a la Alegoría de la Vanidad que se encuentra en Viena, destaca porque la protagonista es María Magdalena. Si bien en un principio se pensaba que únicamente se trataba de una alegoría de la penitencia, al analizar los elementos de la obra vieron la relevancia del personaje representado, entre ellos, la larga melena, las rosas o los elementos de joyería rotos en referencia a su vida de lujuria. Del mismo modo, la escena que aparece al fondo se ha querido ver como una lucha entre el amor celestial y el amor profano, también en referencia a la lucha entre la vida anterior de la santa y la que pretendía llevar tras su penitencia ${ }^{57}$. A pesar de ello, es curioso cómo la obra no presenta los elementos iconológicos que Cesare Ripa describe en su manual en relación con este tipo de alegoría ${ }^{58}$.

\footnotetext{
56 H. MACARTNEY, «La colección Stirling Maxwell en Pollok House, Glasgow» en Goya, n 291, 2002, pp. 345-356 57 H. KRELLIG, The National Inventory of Continental European Paintings. Visual Arts Data Service, University for the Creative Arts. Recuperado de https://vads.ac.uk

58 C. RIPA, Iconología (2 vols.), Akal, Madrid, 2007.
} 
A pesar de las similitudes con las otras alegorías de Pereda, la gran diferencia en la representación de los objetos ha hecho que se cuestionara la atribución, pues hace difícil la relación con la tradición de las naturalezas muertas o los bodegones del siglo XVI en España, por lo que algunos estudiosos han querido ver una obra italiana. Para esta nueva atribución se han señalado dos precedentes italianos, por un lado la María Magdalena de Caravaggio, la primera representación de la santa sin los elementos iconológicos fijados como el cráneo o la vasija rota ${ }^{59}$; o las iconografías creadas por Domenico Fetti, especialmente Lameditación o Melancolía en la Academia Veneciana, de hecho, ésta fue confundida en el documento de compra con una María Magdalena, debido a sus similitudes o la obra Niña durmiendo del Museo de Bellas Artes de Budapest ${ }^{60}$. Así, citando a Krellig, mientras el cuadro de Caravaggio proporciona el modelo de María Magdalena Penitente despidiéndose de su vida anterior, sin mostrar sus atributos tradicionales, el segundo es sin opción a error, el modelo para la figura femenina apoyándose sobre la mesa en actitud de melancolía odolor ${ }^{61}$.

Por otra parte, fijándonos en el grupo escultórico Apolo y Cupido de François Duquesnoy que aparecen en la pintura, la atribución italiana es echada por tierra, asumiendo que parte de esta serie escultórica pertenece a la Colección Real Española y se encontraban en el Palacio Real de Madrid, lugar que Pereda utilizaba para encontrar modelos para sus obras. La exactitud de las formas indica la observación de la escultura en directo o de grabados muy exactos de ésta ${ }^{62}$.

Contigua a la Sala de Música encontramos una habitación con las paredes revestidas de madera que alberga un cuadro de grandes dimensiones titulado Felipe IV y su reina en una columnata (Fig. 2). Esta obra era atribuida en el momento de la compra a la escuela de Velázquez, pero posteriormente se atribuyó a Juan de la Corte.

59 K. KRÜGER, «Mirada interior y misterio estético: Magdalena de Caravaggio» en Escenario Barroco, Imorde Editorial, Emsdetten/Zúrich, 1999.

60 La obra Niña durmiendo ha cambiado la atribución, el académico Roberto Longhi propuso al autor florenitno Sigismondo Coccapani, pero otros académicos, como Roberto Contini duda de esta atribución de ambas obras, incluida la de Pollok. En lo que ambos académicos coinciden es en que, con casi total seguridad, el autor de esta obra sería el autor de la Magdalena de la colección Pollok. Véase el catálogo de la exposición dedicado al artista italiano E. SAFARIK, Domenico Fetti 1588/89-1623, Electa, Milán, 1996.

61 While thepainting by Caravaggioprovides themodel of MaryMagdalen Repentant takingleavefrom herformer life, without showing her traditional attributes, the second is unmistakably the model for the female figure leaning in melancholy or sorrow over the table, texto original de Heiner Krellig en The National Inventory of Continental European Paintings. Visual Arts Data Service, University for the Creative Arts Recuperado de https://vads.ac.uk/large.php?uid=87642

62 Ibídem. 


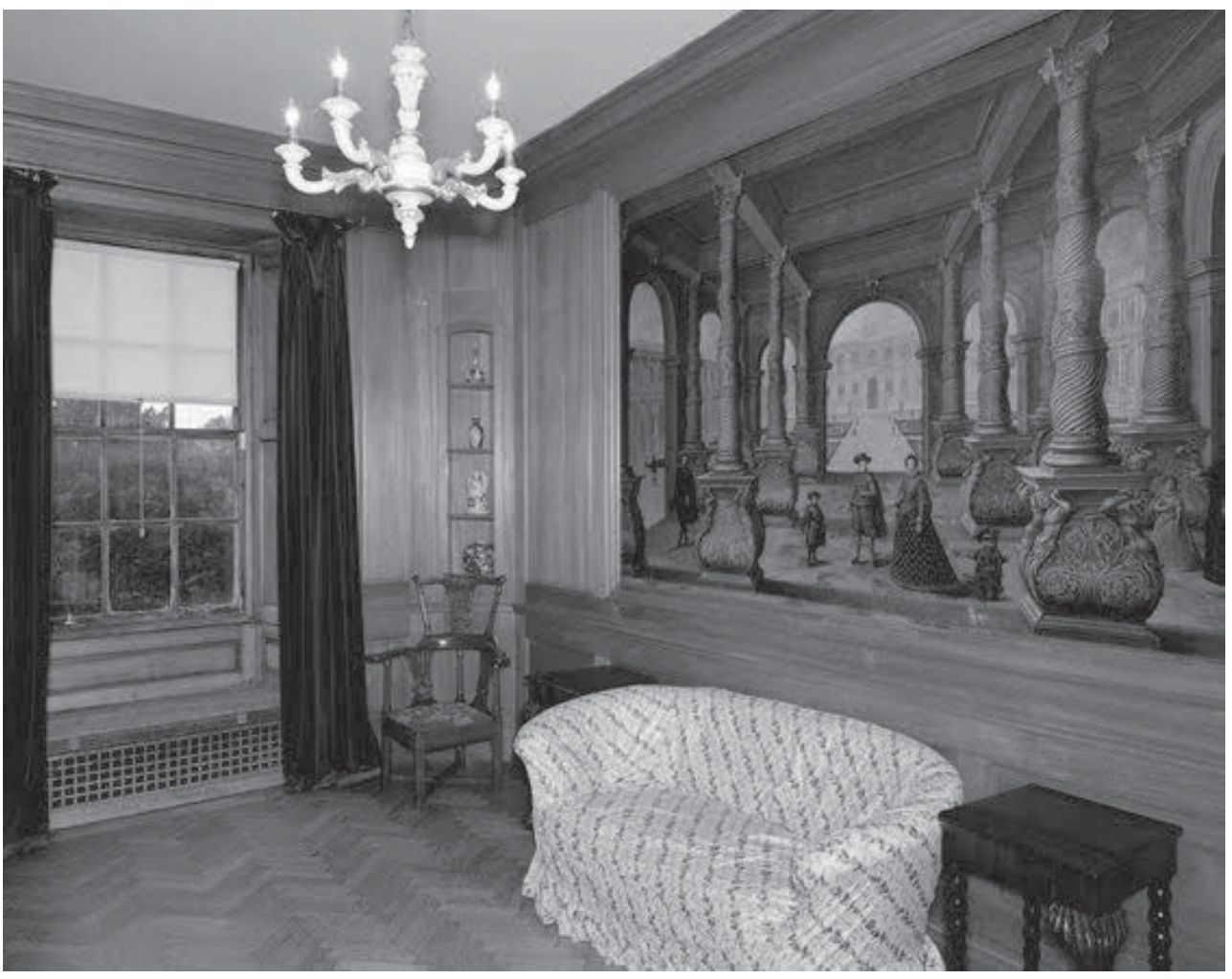

Fig. 2. Obra de Felipe IV y su reina en una columnata en la Sala de cedro.

Esta sala, denominada Cedar Room o Sala de Cedro, fue revestida en 1929 con paneles de madera con la finalidad de convertirla en una sala de fumadores, contigua a la sala de estar.

Si bien la sala alberga otras obras, destaca por sus dimensiones la ya nombrada. Ésta fue adquirida en una subasta de 1851, procedente de la colección del general Meade. La obra muestra un amplio espacio diáfano repleto de enormes columnas salomónicas, con techumbre de madera con casetones, y extensos vanos formados por arcos de medio punto que dan a un jardín exterior. No se podría definir como un templo o un edificio en sí, sino más bien como una construcción exterior pensada para el paseo o la reunión. Entre las columnas encontramos a Felipe IV con su familia, Isabel de Borbón y el príncipe Baltasar Carlos y un bufón de espaldas, a su derecha 
podemos apreciar la figura del Conde Duque de Olivares, y en el lado opuesto doña Inés de Zúñiga, acompañada de la hija del matrimonio.

Atendiendo a la edad del príncipe, se ha estimado que la obra fue realizada alrededor de 1635, lo que se ha utilizado para poder ubicar el espacio arquitectónico donde se encuentran los personajes. Si bien la gran columnata no corresponde a ninguno de los palacios de los que el rey hizo uso en Madrid, el Palacio del Buen Retiro estaría en construcción en la fecha de la realización de la pintura, por lo que se ha querido ver la presencia de Olivares como una señal de su papel en el proyecto constructivo de dicho palacio. En 1632 el conde duque ideó un gran palacio con una segunda plaza, la Plaza Grande, iniciada en 1634, reservada a festejos y rodeada de amplios jardines, como podemos intuir en el lienzo ${ }^{63}$. La construcción de columnas salomónicas a modo de gran baldaquino se ha relacionado con una construcción a modo de templo de la Jerusalén Celestial, así se menciona, de hecho, en el panel de Art Focus que se expone delante de la obra en la casa. Se han buscado los motivos que llevaron a la comisión de esta obra en relación a un auto sacramental que Calderón de la Barca escribió con motivo del Corpus Christi de 1634, titulado El nuevo Palacio del Retiro, bajo encargo del propio Olivares. Este texto supuso una argumentación política y teológica del sentido simbólico del Palacio que se estaba construyendo, pues hay que tener en cuenta que el antiguo Cuarto Real había recibido muchas críticas por no ser digno de un monarca ${ }^{64}$. En el texto, el palacio aparecía como el Templo de Salomón, con doce puertas y doce columnas:

Sufábrica dorada/en doce piedras se miró fundada./Doce puertas abiertas están; al aquilón miran tres puertas, al austro tres se rompen blandamente, / tres al ocasoy tres hacia el oriente, /y todas doceiguales, /guarnecidas de cándidos cristales / en quien mi Ley conoce / doce vislumbres de mis tribus doce. / ¿Qué fábrica ésta ha sido? / ¿Para quién, para quién se ha prevenido/esta casa, este templo, / última maravilla sin ejemplo? ${ }^{65}$

\footnotetext{
63 J. BROWN, "El Palacio del Buen Retiro: un teatro de las artes" en A. ÚBEDA DE LOS COBOS (ed.), $E l$ Palacio del Rey Planeta. Felipe IV y el Buen Retiro, Museo Nacional del Prado, Madrid, 2005, p. 70.

64 J. BROWN y J. ELLIOT, Un palacio para el rey. El Buen Retiro y la corte de Felipe IV, Taurus, Barcelona, 2003.

65 P.CALDERÓN DE LA BARCA, El nuevo Palacio del Retiro. Edición digital a partir de la publicación de A. K. PATERSON, Universidad de Navarra, Kassel Reichenberger, 1998, Biblioteca Virtual Miguel de Cervantes. Recuperado de http://www.cervantesvirtual.com/nd/ark:/59851/bmc90222
} 
Algunos autores hablan incluso de esta estructura arquitectónica como una posible construcción efímera para la celebración de la fiesta para la que Calderón escribió su auto ${ }^{66}$.

Respecto a su autoría, si bien esta obra fue adquirida por Maxwell como un lienzo de la escuela de Velázquez, el catedrático especialista en arte Barroco, Martínez Ripoll la atribuyó al flamenco Juan de la Corte en el año 1981, a pesar de ello, Pérez Sánchez y Angulo Íñiguez no aceptaron esa autoría ${ }^{67}$.

En la planta baja, atravesando la casa de norte a sur, encontramos un gran pasillo que se divide en tramos por arcos de medio punto sujetos por dobles columnas, a modo de arcos triunfales, y en cada uno de estos tramos encontramos estanterías que ocupan toda la pared. Si bien esta biblioteca no puede hacer frente a la que el padre de John Stirling ideó en Keir, el primogénito quiso mantener la esencia letrada de la colección paterna.

A lo largo de la biblioteca (Fig. 3) hallamos varias chimeneas, sobre las cuales se encuentran algunas de las obras españolas más importantes de la colección: la Inmaculada del taller de Murilloy La dama del armiño y Retratodehombredesconocido de El Greco.

Cuando el hispanista adquirió el lienzo de la Inmaculada, la atribución era al artista sevillano, aunque con el tiempo cambió hasta atribuírsela a su taller, como una copia de la cabeza de la Inmaculada Concepción, apodada La Colosal, pintada por Murillo para el convento de franciscano que se demolió en el siglo XIX y que se encuentra actualmente en el Museo de Bellas Artes de Sevilla. Probablemente ambos lienzos fueran pintados - al igual que el que pintó para el Hospital de los Venerables y que, tras pertenecer a la colección del mariscal Soult durante el siglo XIX, volvió a España y hoy se encuentra en el Museo del Prado ${ }^{68}$ — como consecuencia de la emi-

\footnotetext{
66 I. RODRÍGUEZ, y V.MÍNGUEZ, "Olivares y la escenificación del poder a través de la arquitectura”, Potestas, $\mathrm{n}^{\circ}$ 7, 2014, pp. 159-177, siguiendo la estela de A. MARTíNEZ RIPOLL, "Juan de la Corte. Un pintor flamenco en el Madrid de Calderón" en Goya, no 161, 1981, pp. 312-320 o a M. SIMAL LÓPEZ, "El Palacio del Buen Retiro (1633-1648)" en Librosdelacorte.es, $\mathrm{n}^{\circ} 5,2012$, pp. 124-132, ésta última, de hecho, titula en su artículo la obra bajo el nombre La familia real visita una arquitecturaefimera construida en el patio del caballoguiados por el conde-duque de Olivares, fechándola entre 1635-1640.

$67 \quad$ A. MARTÍNEZ RIPOLL, “Juan de la Corte. Un pintor flamenco... op. cit.” en Goya, n 161, 1981, pp. 312-320.

68 Véase página web de la ciudad de Sevilla.http://www.sevillacitycentre.com/la-inmaculada-de-murillo/
} 


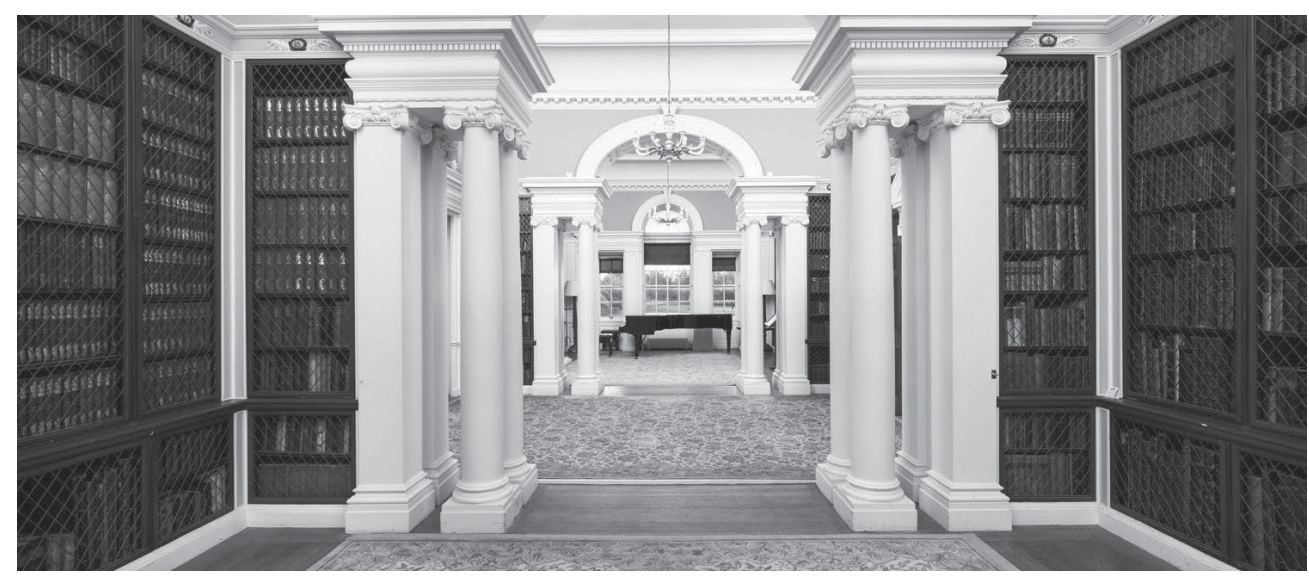

Fig. 3. Biblioteca de Pollok House. Fotografía de Neale Smith (C)

sión del estatuto de 1661 del papa Alejandro VII, en el cual declaraba la inmunidad de la Virgen María frente al pecado original. Esto conllevó a una oleada de encargos de obras de Madonnas e Inmaculadas Concepción ${ }^{69}$.

La obra de unos sesenta por cuarenta y cinco centímetros aproximadamente fue comprada en la subasta de la colección del General Meade, según una nota del propio Stirling ${ }^{70}$. Éste había visto algunas inmaculadas de Murillo a su paso por Sevilla, por lo que no pudo dejar de adquirir una cuando estuvo a su alcance.

La ubicación privilegiada a lo largo de la biblioteca de las obras del Greco no deja evidencia de la relevancia que tenían en la colección paterna, así como en la colección Pollok. Sin duda, La dama del armiño supone la pieza más enigmática e irremplazable de la colección escocesa. El retrato femenino, expuesto durante diez años en la Galería Española del Museo del Louvre supuso un punto de inflexión en el aprecio hacia el Greco, no sólo dentro de la colección real francesa, sino respecto a cientos de visitantes europeos que comenzaron a admirar la figura y destreza del pintor a través de esta dama, a la que se consideraba su hija — si bien el pintor nun-

\footnotetext{
6) H. KRELLIG, The National Inventory of Continental European Paintings. Visual Arts Data Service, University for the Creative Arts. Recuperado de https://vads.ac.uk

to Comprada en subasta en Southam en 1850, en el lote 222. Referencia T-SK 28-11.
} 
ca tuvo hija alguna - ${ }^{71}$. Entre estos visitantes estuvo el escocés, quien durante la investigación para su obra teórica visitó repetidas veces la exposición, igualmente, en sus viajes a España en 1842 y 1845 pudo visitar Toledo y admirar algunas otras obras del Greco.

Ambas piezas las adquirió Stirling en la venta de la colección del rey Luis Felipe de 1853, en Londres. Con toda probabilidad, el retrato de la Dama del armiño fuera la obra por la que más dinero llegó a pagar el escocés de prácticamente toda su colección, pues es reseñable como, a pesar de su poder adquisitivo y su interés en muchas de las obras artísticas que compró, no tendía a invertir grandes sumas de dinero $^{72}$. Quizá el motivo para alcanzar esta suma se debiera al fuerte impacto que la obra causó sobre sir William. En sus Anales escribiría respecto a esta obra:

\section{Elretrato desu hija esuna de lasjoyas más puras e inclusoen la Galería} Real de Madrid sería una joya. Está pintada en la flor de su vida y de su belleza; sus ojos oscuros y su tez rica son finamente complementados por el manto de piel blanco que cubre su cabeza; y su semblante, en cuya representación su padre afectuoso ha manifestado su mayor destreza, es uno de los más hermosos que jamás la muerte ha desvanecido y que el pincel ha rescatado de la tumba ${ }^{73}$.

Los dos lienzos se caracterizan por la profundidad psicológica en las miradas de los retratados, si bien mientras la técnica de pincelada suelta y la paleta de tonos

71 C. MARINAS, La galería española ... op. cit., pp. 129-152.

Para hacernos una idea del impacto que supuso esta pobra en el aprecio por el pintor cretense, a continuación, se van a enumerar algunas de las exhibiciones de las que ha formado parte en calidad de préstamo dicho retrato, todo recogido por KRELLIG:

Art Treasure, Manchester, 1857, cat. no. 234; National Exhibition of Works of Art, Leeds, 1868, cat. no. 325; Winter Exhibition, Royal Academy de Londres, 1872, cat. no. 112; Exhibition of Spanish Art, New Gallery, 1895-99, cat. no. 81; Exhibition of the Works of Spanish Painters, Guildhall Art Gallery, Londres, 1901, cat. no. 77; Burlington Club, Londres, 1904, cat. no. 17; Spanish Old Masters, Grafton Galleries, Londres, 1913-14, cat. no. 128; National Gallery of Scotland, Edimburgo, 1922; Exhibition of Spanish Paintings, National Gallery,Londres, 1947, cat. no. 15; Spanish Paintings from El Greco to Goya, National Gallery of Scotland, Edimburgo, 1951, cat. no. 14; Manchester Art Treasures Centenary Exhibition, Manchester, 1957, cat. no. 148; Paintings from Pollok House, Glasgow Art Gallery and Museum, 1960-61; Paintings from Glasgow Art Gallery: A Loan Exhibition of the National Art-Collections Fund, Wildenstein, Londres, 1980, cat. no. 14; El Greco: Mystery and Illumination, National Gallery of Scotland, Edimburgo, 1989, cat. no. 17; La Prima Donna pittrice: Sofonisba Anguissola: Die Malerin der Renaissance (um 1535-1625) Cremona-Madrid-Genua-Palermo, Kunsthistorisches Museum, Viena, 1995, cat. no. 41, como Anguissola; Visions of Spain: Paintings from the Stirling Maxwell Collections, Burrell Collection, Glasgow, 1995-96; Felipe II: Un monarca y su época. Un príncipe del Renacimento, Madrid, Museo del Prado, 1998-99, cat. no. 234; El Greco: Identidady transformación: Creta. Italia. España, Museo Thyssen Bornemisza, Madrid, 1999-2000, cat. no. 27; El Greco, Metropolitan Museum of Art, Nueva York, 2003-04, cat. no. 73.

72 Por la Dama del armiño pagó 133 libras. Para hacernos una idea, por el otro retrato del Greco, pagó 10. Referencia T-SK $28 / 10$

73 W.STIRLING, Annals... op. cit., p. 285. 


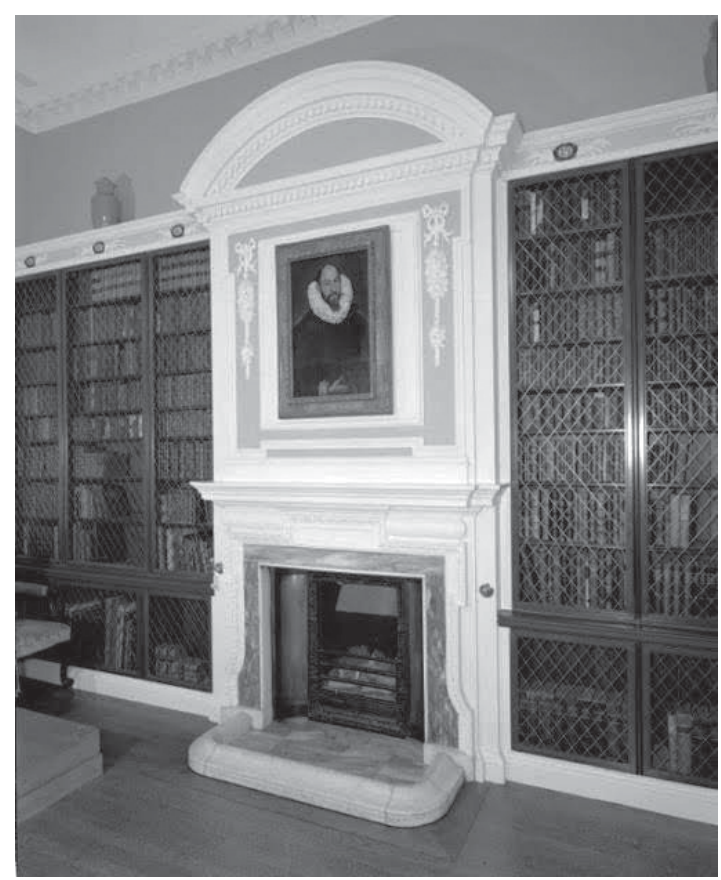

Fig. 4. Retrato de cabellero desconocido sobre una de las chimeneas de la biblioteca.

pardos y blancos y negros vibrantes del Caballero desconocido (Fig. 4) no da lugar a confusión en la atribución, la pincelada mucho más homogénea en la carne y las telas de la Dama del armiño ha provocado que se hayan sucedido las atribuciones ${ }^{74}$.

Para finalizar este recorrido por algunas de las obras más destacadas de las exhibidas en Pollok House es imprescindible mencionar el lienzo que encontramos en lo alto de la escalera que sube al primer piso, la obra de Martínez Gradilla Felipe IV como defensor del arte de la pintura, que puede verse desde tanto desde el piso inferior como desde el piso superior (Fig. 5 y 6), encontrándose en una posición privilegiada en la casa.

\footnotetext{
74 Para el debate sobre la atribución de la Dama del armiño, véase el proyecto Unwrapping an icon ya nombrado, y E. HARRIS, “El Greco's Fortuna Critica in Britain” en N. HADJINICOLAOU (dir.), El Greco of Crete: Proceedings of the International Symposium, Iraklion, Crete, 1-5 September 1990, Iraklion: 1995, pp. 481-497, reeditado en 2010 por Glendinning y Macartney, pp. 240-252.
} 
El lienzo es una alegoría de las artes, en él aparece un retrato de Felipe IV inserto en un marco ovalado, flanqueado por dos niños representantes de las bases científicas de la pintura: uno sostiene una paleta y pinceles y el otro un pergamino con dibujo de anatomía. Sobre el retrato, dos putii alados con trompetas que sujetan algunos de los tratados más relevantes de la pintura del Siglo de Oro. Delante del rey, en un plano privilegiado, el tratado de las Vidas de Giorgio Vasari. ${ }^{75}$ En la parte inferior hay una inscripción: Fui con tal gusto en migrei/de tal ateprofesor/que entrela una yotra lei/por ser sin duda pintor/aun dexara de ser rei [sic]. Esta quintilla hablaba de la labor del rey Felipe IV, que había muerto el año anterior, como protector de las artes y distinguir la nobleza de la labor hasta el punto de practicar él mismo la pintura. Al mismo tiempo habla de la liberalidad de las artes, utilizando el término profesor, diferenciando a los pintores de los artesanos ${ }^{76}$.

La pintura fue realizada por Martínez Gradilla para la Academia fundada en Sevilla por Murillo en 1660. El autor, quien sería mayordomo en 1662 y 1666 y cónsul en 1668 y 1669, realizó la alegoría en 1666 para donarla a la Academia, según Macartney, la realización y donación de una obra podría ser un acto que se esperara de los mayordomos ${ }^{77}$.

La obra fue comprada por Stirling en Londres en 1851, probablemente no por tratarse de uno de los mejores retratos de Felipe IV, sino por el simbolismo y el sentido que tenía, como muestra de la fundación de la Academia de Sevilla y todo el círculo erudito que se reunía para dibujar del natural, desarrollando en la ciudad andaluza una escuela de gran relevancia ${ }^{78}$; así como por ser el reflejo de una de las teorías más importantes entre los artistas del Siglo de Oro y el ámbito de la pintura a la vez que destaca el papel de defensor y promotor de las artes delrey.

\footnotetext{
75 H. MACARTNEY, «Sir William Stirling Maxwell: Scholar of Spanish Art» en Espacio, Tiempo y Forma, $\mathrm{n}^{\circ} 12$, 1999, pp. 287-316.

76 J. GALLEGO, El pintor, de artesano a artista, Diputación Provincial, Granada, 1996, p. 122.

77 Sobre la Academia de Sevilla y esta obra en particular véase ibídem, pp. 310-316; H. MACARTNEY, "The Nobility of Art: The Seville Academy founded by Murillo and a Portrait of Philip IV at Pollok House" en Journal of the Scottish Society for Art History, no 4, 1999, pp. 48-57; E. VALDIVIESO, Historia de la pintura sevillana, Guadalquivir ediciones, Sevilla, 2002, p. 255; y D. GARCÍA LÓPEZ, "Lectores de Vasari en la España de la Edad Moderna. En busca de un modelo para las vidas de artistas españoles", Goya, n³ 342, 2013, p. 35.

78 Ibídem.
} 

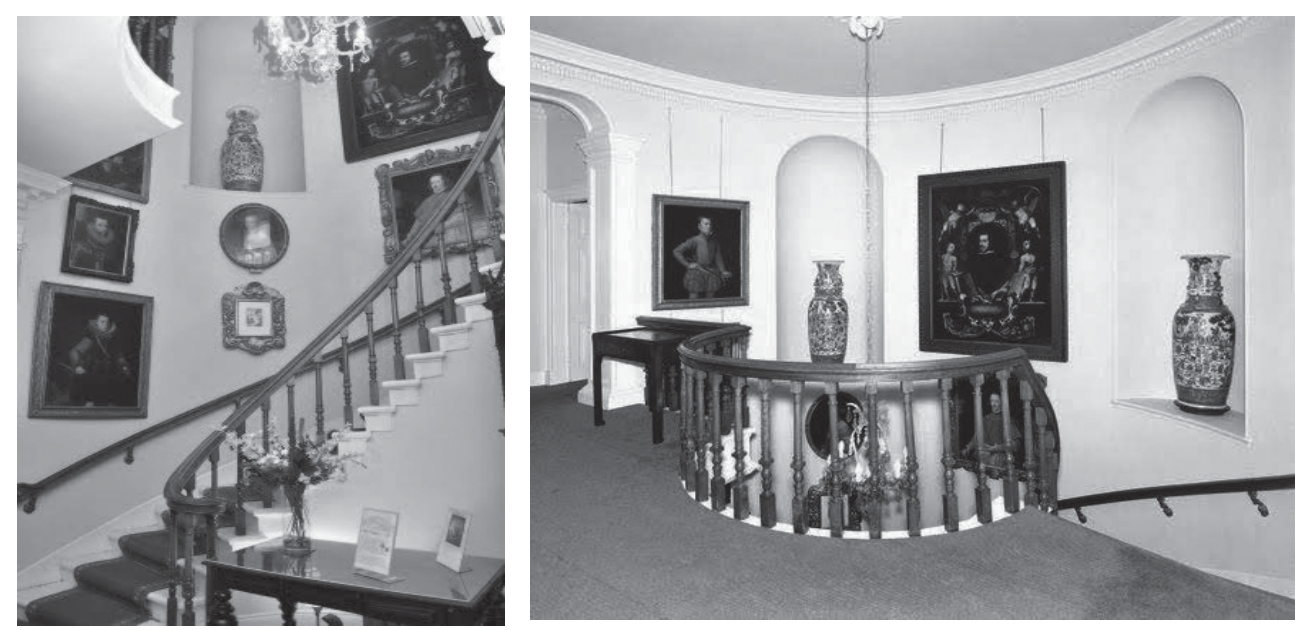

Fig. 5 y 6.FelipeIV como defensor del arte de la pintura, ca. 1665-66 ubicada en lo alto de la escalera.

Como ya adelantamos, este recorrido no supone más que un pequeño porcentaje de las piezas españolas dentro de Pollok, pero bien por su ubicación destacada o por la relevancia histórico-artística que conllevó en su momento la adquisición de dichas piezas, se ha visto oportuno destacarlas, realizando así un acercamiento a la colección total, con la intención de lograr una visión general sobre la colección Pollok de arte español, ubicada a las afueras de Glasgow, como una de las muestras más representativas de la situación que sufrió el coleccionismo europeo en el siglo XIX. Subrayando, al mismo tiempo, esta actividad como forma de expandir fronteras y de dar a conocer la historia y cultura de lugares desconocidos yolvidados.

En esta labor, es esencial destacar el papel de sir William Stirling Maxwell para la difusión del arte y la historia de España en todo Reino Unido, así como para el cambio de visión en un principio oscura y condescendiente, y más tarde exótica y romántica, gracias a su obra Anales de Artistas de España, que se convertiría en una de las más notables obras historiográficas sobre artistas españoles en el mundo anglosajón, marcando el precedente tanto en las obras cronológicas, como en el uso de la fotografía como forma de difundir la Historia del Arte.

Así, a pesar de que tras la muerte de Stirling, la colección inicial se dispersara, la colección Pollok heredada por su hijo mayor supone una muestra irremplazable 
del movimiento del mercado artístico decimonónico y de la entrada del arte español en éste. Si bien los motivos de John Stirling para conservar la colección no fueran los mismos que llevaron a su padre a formarla, la situación que hoy encontramos en Pollok House es muestra del prestigio que suponía a lo largo del siglo XIX y posteriormente, ya entrados en el siglo XX la posesión de arte español, en especial de los siglos XVI y XVII. 